cotton fabric in protecting the latter against actinic attack. While the details of the technique of investigation and the results obtained, particularly on the chemical aspect of protection/deterioration of cellulose, are reserved for a future publication, it is the object of the present note to direct attention to the remarkable effect of manganese (as oxide) in inhibiting actinic deterioration.

The metals investigated were chromium, copper, iron, manganese, tin, titanium and aluminium. Three different concentrations of the metals, approximately $0.05,0.5$ and 1 per cent on the weight of fabric, were studied. Dosootie, a fabric of Indian tentage, was used. The metals were deposited as their oxides on the fabric by a double-bath process involving initial treatment in a soluble salt solution and sub. sequent decomposition with aqueous solution of alkali. The treated fabrics and untreated control pieces were exposed during hours of sunshine at Kanpur (lat. $26^{\circ} 26^{\prime}$ N., long. $80^{\circ} 22^{\prime}$ E.) for a total period of 2,400 hours. Samples were drawn according to a randomized plan initially and at intervals of 400 hours. Bursting-strength determinations were carried out at each sampling.

The results showed that manganese $(0.56$ and 1.3 per cent) on fabrics retards in a remarkable manner the course of actinic degradation; there is possibly a critical concentration of manganese above which only the protective effect is apparent. Although iron and aluminium in the higher concentrations $(0.84$ and $\mathbf{0 . 4 5}$ per cent respectively) show some protective effect in the very early stages of exposure, they are not useful. Fabrics containing chromium in the higher concentrations $(0.8 \mathrm{per}$ cent) generally follow the pattern of the control in the rate of degradation. Copper, tin and titanium accelerate degradation, the effect being most marked in the case of copper and titanium.

While the result with copper is not surprising, the behaviour of manganese in inhibiting actinic degrada. tion has considerable practical possibilities. Confirmatory experiments on this are in progress.

$$
\begin{aligned}
& \text { S. L. Perti } \\
& \text { S. K. Ranganathan } \\
& \text { T. S. SUBramantan } \\
& \text { L. R. SUD }
\end{aligned}
$$

Technical Development Establishment, Laboratory (Stores), Kanpur. Nov. 22.

\footnotetext{
1 Wagner, Webber and Siu, Arch. Biochem., 12, 35 (1947).

"Ramsbotham, J. E.," "The Fire-prooflng of F abrics" (H.M. Stationery Office, 1947)

'Cunliffe, P. W., Shirley Inst. Mem., 2, 244 (1923).
}

\section{Preparation of Ferric Succinate Jellies}

IT is well known that a neutral solution of succinic acid gives a brownish-red precipitate of ferric succinate with a ferric chloride solution. Handl ${ }^{1}$ obtained brownish-red crystals of ferric succinate by treating a ferric chloride solution with a solution of sodium succinate. We have now succeeded in preparing ferric succinate jellies.

The jellies have been obtained by the metathetical reactions between ferric chloride and sodium succin. ate. A ferric chloride solution containing $17.54 \mathrm{gm}$. of ferric oxide per litre and a 5 per cent solution of sodium succinate were found to give the best jellies. To 4 c.c. of the ferric chloride solution were added different amounts of the sodium succinate solution. The total volume was kept at 6 c.c. in each case. The mixtures were shaken for about thirty seconds and then allowed to stand in a bath maintained at

\begin{tabular}{|c|c|}
\hline $\begin{array}{c}\text { Amount of sodium succinate } \\
\text { (c.c.) }\end{array}$ & $\begin{array}{c}\text { Time of setting } \\
(\mathbf{h r} \text {.) }\end{array}$ \\
\hline $\begin{array}{l}2 \cdot 0 \\
1.9 \\
1.8 \\
1.7 \\
1.6 \\
1 \cdot 4 \\
1 \cdot 2 \\
1 \cdot 0\end{array}$ & $\begin{array}{r}1 \\
2 \\
4 \\
6 \\
9 \\
15 \\
24 \\
36\end{array}$ \\
\hline
\end{tabular}
$25^{\circ} \mathrm{C}$. The influence of the varying amounts of sodium succinate on the time of setting of the jellies was recorded.

These jellies, like the jellies of fferric phosphate and ferric arsenate investigated by Prakash ${ }^{2}$, and of thorium borate investigated by Mushrans, are trans. parent, firm and perfectly stable. It is, however, interesting to note that whereas the other transparent jellies of ferric salts have been obtained by the dialysis of their sols and subsequent coagulation with suitable electrolytes, ferric succinate is the only jelly of iron so far known which has been obtained in a perfectly transparent state by the metathetical process. These jellies do not exhibit any syneresis and maintain their transparency even when kept for a long time. They set more readily at higher temperatures than at low, but lose their uniformity of texture and become opaque when allowed to set at high temperatures.

Satya Prakash

S. P. Mushran

Chemical Laboratories,

University, Allahabad. Nov. 20.

1 Handl, "Jahresbericht über die Fortschritte der Chemie", 279 (1859). 2 Prakash and Dhar, J. Ind. Chem. Soc., 6, 391 (1929).

${ }^{3}$ Mushran, Nature, 158, 95 (1946).

\section{Genetical Differences in Taste Sensitivity to Phenylthiourea and to Anti-thyroid Substances}

Fox $^{x}$ first observed that people differed in their ability to taste phenylthiourea, and it was found (Blakeslee and Salmon ${ }^{2}$, Blakeslee ${ }^{3}$, Snyder ${ }^{4}, 5$ ) that these differences were genetically determined. The distribution of taste thresholds to this substance in all populations so far studied has been found to be bimodal. Familial investigations indicate that the two classes of individuals, 'tasters' and 'non-tasters', that is, those relatively sensitive and those relatively insensitive to phenylthiourea, differ in respect of a single gene pair, the 'tasters' being homozygous or heterozygous for the dominant allele, the 'non-tasters' homozygous for the recessive allele. Between one quarter and one third of all individuals tested in various populations appear to fall into the recessive class. Fisher, Huxley and Ford ${ }^{6}$ have described observations which suggest that similar differences may exist among anthropoid apes. They have pointed out that this implies the existence of a stable, balanced polymorphism, and that, for such a system to occur, the heterozygotes should have had some selective advantage over the two types of homozygotes.

The taste sensitivity to phenylthiourea has beer. found to show only slight correlation or no correlatior at all with taste sensitivity to some other bitter sub. 